\title{
The Relationship between Personality and Emotional Intelligence: An Exploratory Case of Brunei Student Teachers
}

\author{
Lawrence Mundia \\ Sultan Hassanal Bolkiah Institute of Education, Universiti Brunei Darussalam, Jalan Tungku Link, Gadong BE 1410 \\ Bandar Seri Begawan, Brunei Darussalam; Email: lawrence.mundia@ubd.edu.bn
}

\section{Doi:10.5901/mjss.2015.v6n6s1p133}

\begin{abstract}
The exploratory case study investigated the relationship between personality and emotional intelligence using a random sample of Brunei student teachers $(N=61)$ with 52 females and 12 males. Data were collected by the Myers-Briggs Type Indicator (MBTI) and the BarOn Emotional Intelligence (EI) scale - Youth Version. Two of the $16 \mathrm{MBTI}$ personality types were not represented in the participants. Personality preferences and emotional intelligence domains were not highly related dispositions. Low and high scoring MBTI personality types on the six subscales of the El measure were identified and mean scores interpreted. Different MBTI personality types used different kinds of emotional intelligence. The most common form of El strategy used by the majority of the personality types (8) was general mood followed by adaptability (5 types). Overall, each EI variable was used highly by at least three different MBTI personality types. Further large-scale research was recommended to gain additional insights.
\end{abstract}

Keywords: MBTI; personality preferences; personality types; emotional intelligence; student teachers.

\section{Introduction}

The concepts of personality and emotional intelligence refer to different notions of interacting and relating with others in given contexts or environments. Personality has been defined in many different ways but none of the definitions is universally dominant. Some psychologists say it refers to individual differences in characteristic patterns of thinking, feeling and behaving (Goleman, 1995). Others argue that it is the combination of characteristics or qualities such as traits and other mechanisms that form an individual's overall distinctive disposition and influence the person's interactions and adaptations with the environment (Larsen \& Bus, 2002). These differences in definition have partly contributed to the emergence of numerous approaches to the study of personality. On the other hand, emotional intelligence (EI) is the ability to properly recognize one's own and other people's emotions, discriminate between different feelings and label them appropriately, and use emotional information accurately to guide thinking and behavioral actions (Salovey \& Mayer, 1990; BarOn \& Parker, 2000). People who are high in El often have a well-developed awareness of the inner-self, engage in self-reflection and self-direction, and are at ease to giving or receiving constructive feedback (Sing, 2015).

\subsection{Psychological studies on Brunei students}

Studies that directly examine the relationship between personality and emotional intelligence in the Brunei social context were still rare, if not non-existent at the time of conducting the present research. However, one related recent study that dealt with Brunei student teachers of different personality-orientation found that the trainee teachers had psychological problems of an emotional nature such as depression, anxiety and stress (Mundia, 2010a). There is also evidence from research that anxiety and stress were experienced by Brunei secondary school students (see Hamid et al, 2013 and Matzin et al, 2013). If these emotionally-loaded personal problems were prevalent in small groups of Brunei trainee teachers and secondary school students, they may by extrapolation, also be numerous and common in the general Brunei society or population. In another investigation of a different group of Brunei student teachers, the results showed that the trainees used a wide range of strategies when addressing their personal psychological and educational problems that included task-oriented, emotion-oriented, and avoidance-oriented tactics (Mundia, 2010b). These findings suggest that there might be some sort of relationship between personality and other attributes such as emotional intelligence. Under the ongoing National Education System for the $21^{\text {st }}$ Century (also known as Sistem Pendidikan Negara Abad Ke21 in Bahasa Melayu language or SPN21) educational reforms in Brunei, teachers are required to play a central role in assessing learning not only quantitatively but also qualitatively by examining students' personal traits that might impact 
learning either positively or negatively (Mundia, 2010c). In view of this, Brunei teacher education has now been reformed to ensure that trainee teachers receive adequate psychometric skills required in assessing students both qualitatively and quantitatively (Mundia, 2012; Tait \& Mundia, 2012).

\subsection{Objectives of the study}

The present study addressed four main objectives, namely to:

(a) Determine the links between MBTI personality preferences and BarOn emotional intelligence variables.

(b)Determine the scores of MBTI personality types on the intrapersonal and interpersonal El variables.

(c) Determine the scores of MBTI personality types on stress management and adaptability El variables.

(d) Determine the scores of MBTI personality types on general mood and positive impression El variables.

\section{Method}

The design, sample, instruments, procedures, and data analyses for the present study are briefly described below under separate subheadings.

\subsection{Design}

The present study used the field survey method to address the objectives of the study. This strategy differs from other survey approaches (such as online, postal and telephone surveys) in that data are collected directly by the researcher or assistants in the natural ecological environments where participants are found. The design also enables researchers to give on-the-spot instructions and clarifications regarding completion of data collection instruments correctly thereby increasing the number of useful returns.

\subsection{Sample}

During the academic year when the present study was conducted in Brunei, there were 77 students enrolled in the first semester of the Master of Teaching (MTeach) degree program. The random sample $(N=64)$ for the present study consisted of $52(81 \%)$ females and $12(19 \%)$ males enrolled in the first semester of the MTeach program. There were no other inclusion and exclusion criteria. Their age ranged from 21 to 37 (Mean $=25.671$; SD = 4.186). The median and modal ages were 25.000 and 23.000 respectively. Thirty five (35) of the participants were below the median age and relatively young while 29 were above the median age. All were training to teach a wide range of subjects taught in the Brunei government schools. Each of the participants possessed an initial degree in her / his subject of teaching specialization.

\subsection{Instruments}

Data were collected by two self-report instruments, namely the Myers-Briggs Type Indicator (MBTI) full scale (Myers, 1962; Briggs-Myers \& Briggs, 1985) with 94 items and the emotional intelligence test - youth version - 60 items (BarOn \& Parker, 2000). The MBTI measures four bipolar personality domains (extroversion-introversion, sensing-intuition, thinking-feeling, and judging-perceiving). Most items were scored dichotomously (A or B) and few had a three-response format (A, B, or $C$ ). The BarOn emotional intelligence test measured six variables (intrapersonal, interpersonal, stress management, adaptability, general mood, and positive impression) on 4-point Likert scales. The youth version of the BarOn El instrument was considered to be suitable for use in Brunei based on two reasons. First, the instrument is written in simple English that does not require translation in the Brunei context. Second, the Ministry of Youth, Culture and Sports in Brunei defines the term "youth" as any person aged between 13 to 40 years. Based on a trial sample (overall $N=51$ ) consisting of similar trainee teachers in the previous cohort, the MBTI personality preferences subscales yielded the nonsignificant test-retest correlation reliability indices (with a one month in-between time interval) presented in Table 1. The subsamples ( $\mathrm{n}$ ) on each dimension differed due to pairwise deletion of cases with missing values. The low but significant positive correlations suggested that high scores on the first occasion of testing were matched with high scores on the second occasion and vice versa. The MBTI personality preferences subscales were thus quite stable and consistently produced nearly the same results when administered to the same individuals in the same environment on two occasions. 
Table 1: Reliability of the MBTI instruments $(N=51)$

\begin{tabular}{|l|c|c|c|}
\hline Scale & Items & n & Test-retest $\mathbf{~}$ \\
\hline Extroversion & 21 & 49 & $0.351^{*}$ \\
\hline Introversion & 21 & 50 & $0.349^{*}$ \\
\hline Sensing & 26 & 48 & $0.337^{*}$ \\
\hline Intuition & 26 & 46 & $0.286^{*}$ \\
\hline Thinking & 23 & 45 & $0.335^{*}$ \\
\hline Feeling & 23 & 50 & $0.274^{*}$ \\
\hline Judging & 24 & 50 & $0.321^{*}$ \\
\hline Perceiving & 24 & 47 & $0.350^{*}$ \\
\hline
\end{tabular}

${ }^{*} p<.05$ (two-tailed)

The inter-correlations in Table 2 show that the MBTI personality preferences scales had adequate discriminant or divergent validity. Most of the correlations were low, negative and insignificant. The few high significant correlations were negative. This was proof that the instruments were conceptually distinct measures of different personality domains.

Table 2: Validity of the MBTI instruments $(N=50)$

\begin{tabular}{|l|c|c|c|c|c|c|c|}
\hline Instrument & $\mathbf{1}$ & $\mathbf{2}$ & $\mathbf{3}$ & $\mathbf{4}$ & $\mathbf{5}$ & $\mathbf{6}$ & $\mathbf{7}$ \\
\hline Extraversion & 1 & & & & & & \\
\hline Introversion & $-0.923^{\star \star}$ & 1 & & & & & \\
\hline Sensing & -0.211 & 0.209 & 1 & & & & \\
\hline Intuition & 0.063 & -0.039 & $-0.760^{\star *}$ & 1 & & & \\
\hline Thinking & 0.145 & -0.123 & -0.042 & 0.116 & 1 & & \\
\hline Feeling & -0.114 & 0.158 & 0.150 & -0.141 & $-0.768^{\star \star}$ & 1 & \\
\hline Judging & 0.025 & 0.014 & 0.229 & $-0.285^{\star}$ & -0.022 & -0.020 & 1 \\
\hline Perceiving & -0.062 & 0.056 & -0.063 & 0.232 & 0.033 & 0.092 & $-0.901^{* \star}$ \\
\hline
\end{tabular}

Information pertaining to the reliability and validity of the BarOn measures is respectively presented in Table 3 and Table 4 below. As noted from these tables, these subscales were suitable for use with Brunei student teachers as shown by the high Cronbach alpha values and valid as indicated by the low positive and negative correlation coefficients.

Table 3: Reliability of the BarOn El measures $(N=50)$

\begin{tabular}{|l|c|c|c|c|c|}
\hline Variables & Items & Mean & Standard Error of Mean & Standard Deviation & Alpha reliability \\
\hline Intrapersonal & 6 & 13.843 & 0.393 & 3.148 & 0.720 \\
\hline Interpersonal & 12 & 36.687 & 0.463 & 3.711 & 0.746 \\
\hline Stress management & 12 & 29.859 & 0.657 & 5.258 & 0.860 \\
\hline Adaptability & 10 & 27.562 & 0.468 & 3.749 & 0.784 \\
\hline General mood & 14 & 41.390 & 0.517 & 4.142 & 0.737 \\
\hline Positive impression & 6 & 14.875 & 0.346 & 2.768 & 0.769 \\
\hline
\end{tabular}

Table 4: Validity of the BarOn emotional intelligence variables $(N=50)$

\begin{tabular}{|l|c|c|c|c|c|}
\hline & 1 & 2 & 3 & 4 & 5 \\
\hline 1.Intrapersonal & 1 & & & & \\
\hline 2.Interpersonal & 0.065 & 1 & & & \\
\hline 3.Stress management & 0.251 & -0.208 & 1 & & \\
\hline 4.Adaptability & 0.029 & 0.106 & $0.286^{*}$ & 1 & \\
\hline 5.General mood & 0.062 & 0.080 & -0.054 & $0.335^{* *}$ & 1 \\
\hline 6.Positive impression & 0.121 & 0.145 & -0.164 & 0.057 & $0.311^{*}$ \\
\hline
\end{tabular}

${ }^{*} p<.05$ (two-tailed)

$\star \star p<.01$ (tw0-tailed) 


\subsection{Procedures}

Ethical conditions for involving trainee teachers in the study were verbally discussed with the participants. These included privacy, anonymity, confidentiality as well as psychological and physical harm. Only students who voluntarily agreed to participate in the study were recruited as respondents for the present study. Students were told about the purposes of the study and no deception was used. Meanings of all difficult words or phrases on the instruments were verbally explained to the participants and instruments did not need to be translated into Bahasa Melayu, Brunei's main and official language.

\subsection{Data analysis}

Both the MBTI and BarOn scales were scored according to instructions in their respective technical manuals. The obtained raw data were analyzed by descriptive statistics, correlation, and One-Way ANOVA.

\section{Results}

The findings are presented below according to the objectives of the study.

\subsection{Connections between MBTI personality preferences and BarOn emotional intelligence variables}

The Pearson correlations in Table 5 show the association between personality preferences and emotional intelligence variables. Only seven pairs of variables correlated significantly with each other in this table (either positively indicated by bold values or negatively shown by bold italic values). The low but significant non-italicized bold positive correlations suggest that the paired variables could directly predict each other to some extent. However, the low but significant italicized bold negative correlations imply that the paired variables could only inversely predict each other to some degree. Although not significantly related, it can be observed from Table 5 that only extroversion had an appreciably high correlation with positive impression.

Table 5: Relationship between MBTI personality preferences and BarOn emotional intelligence variables $(N=60)$

\begin{tabular}{|l|c|c|c|c|c|c|}
\hline Variables & Intrapersonal & Interpersonal & Stress management & Adaptability & General mood & Positive impression \\
\hline Extroversion & $\mathbf{0 . 3 6 8 ^ { * * }}$ & 0.102 & -0.162 & 0.073 & $\mathbf{0 . 2 9 9}^{*}$ & 0.217 \\
\hline Introversion & $-\mathbf{0 . 3 5 9 ^ { * * }}$ & -0.031 & 0.166 & -0.093 & $\mathbf{- . 0 3 4 1 ^ { * * }}$ & -0.191 \\
\hline Sensing & -0.202 & -0.072 & -0.153 & -0.059 & 0.031 & 0.014 \\
\hline Intuition & 0.127 & -0.074 & 0.154 & -0.062 & $-0.277^{*}$ & -0.095 \\
\hline Thinking & 0.199 & $-0.426^{* *}$ & 0.153 & 0.209 & -0.026 & -0.138 \\
\hline Feeling & -0.111 & $\mathbf{0 . 3 2 9 ^ { * * }}$ & -0.063 & -0.112 & -0.008 & 0.122 \\
\hline Judging & -0.009 & -0.019 & 0.118 & -0.022 & -0.019 & 0.088 \\
\hline Perceiving & 0.001 & -0.028 & -0.116 & 0.044 & -0.115 & -0.077 \\
${ }^{*}<.05$ (two-tailed) \\
${ }^{* *} \mathrm{p}<.01$ (two-tailed)
\end{tabular}

\subsection{Performance of MBTI types on intrapersonal and interpersonal El variables}

The mean scores presented in Table 6 were arbitrarily classified as low, medium, or high as shown. Only four MBTI types scored high on the intrapersonal El scale while three types scored high on the interpersonal scale (see bold letters in Table 6). Surprisingly, only the INFJ type (though few) scored high on both of these scales. 
Table 6: Mean scores of MBTI types on BarOn Intrapersonal and interpersonal variables $(\mathrm{N}=61)$

\begin{tabular}{|c|c|c|c|c|c|}
\hline \multicolumn{2}{|c|}{ Emotion / MBTI type $†$} & $n$ & Mean & Std. Deviation & Performance level \\
\hline Intrapersonal & $\begin{array}{l}\text { ESTJ } \\
\text { ESTP } \\
\text { ESFJ } \\
\text { ISTJ } \\
\text { ISTP } \\
\text { ISFJ } \\
\text { ISFP } \\
\text { ENTJ } \\
\text { ENTP } \\
\text { INTJ } \\
\text { INTP } \\
\text { INFJ } \\
\text { Total }\end{array}$ & $\begin{array}{c}8 \\
3 \\
2 \\
13 \\
13 \\
8 \\
3 \\
3 \\
2 \\
2 \\
2 \\
6 \\
7 \\
2 \\
58\end{array}$ & $\begin{array}{l}15.375 \\
16.666 \\
14.500 \\
13.692 \\
14.125 \\
10.666 \\
11.666 \\
15.000 \\
13.000 \\
14.500 \\
13.000 \\
16.500 \\
13.967\end{array}$ & $\begin{array}{l}0.916 \\
3.055 \\
4.949 \\
2.780 \\
3.833 \\
3.214 \\
4.509 \\
1.414 \\
1.414 \\
3.146 \\
2.160 \\
3.535 \\
2.938\end{array}$ & $\begin{array}{c}\text { High } \\
\text { High } \\
\text { Medium } \\
\text { Medium } \\
\text { Medium } \\
\text { Low } \\
\text { Low } \\
\text { High } \\
\text { Medium } \\
\text { Medium } \\
\text { Medium } \\
\text { High } \\
\text { Medium }\end{array}$ \\
\hline Interpersonal & $\begin{array}{l}\text { ESTJ } \\
\text { ESTP } \\
\text { ESFJ } \\
\text { ISTJ } \\
\text { ISTP } \\
\text { ISFJ } \\
\text { ISFP } \\
\text { ENTJ } \\
\text { ENTP } \\
\text { INTJ } \\
\text { INTP } \\
\text { INFJ } \\
\text { Total }\end{array}$ & $\begin{array}{c}8 \\
3 \\
2 \\
13 \\
13 \\
8 \\
3 \\
3 \\
2 \\
2 \\
2 \\
6 \\
7 \\
2 \\
61\end{array}$ & $\begin{array}{l}36.750 \\
35.333 \\
42.500 \\
35.846 \\
35.625 \\
37.000 \\
38.333 \\
36.000 \\
36.000 \\
36.666 \\
36.285 \\
38.500 \\
36.688\end{array}$ & $\begin{array}{l}4.267 \\
4.041 \\
3.535 \\
4.375 \\
5.998 \\
2.645 \\
1.154 \\
0.000 \\
1.414 \\
2.338 \\
2.058 \\
2.121 \\
3.814\end{array}$ & $\begin{array}{c}\text { Medium } \\
\text { Low } \\
\text { High } \\
\text { Low } \\
\text { Low } \\
\text { Medium } \\
\text { High } \\
\text { Medium } \\
\text { Medium } \\
\text { Medium } \\
\text { Medium } \\
\text { High } \\
\text { Medium }\end{array}$ \\
\hline
\end{tabular}

†Two MBTI personality types (ENFJ and ENFP) were not represented in the sample. A further two types (ESFP and INFP) had only one student each and were thus excluded from this analysis

\subsection{Performance of MBTI types on stress management and adaptability El variables}

Evidence in Table 7 shows that three personality types scored high on the stress management scale while five scored high on the adaptability scale. The ENTP and INTP types scored high on both of these scales.

Table 7: Mean scores of MBTI types on BarOn stress management and adaptability variables $(\mathrm{N}=58)$

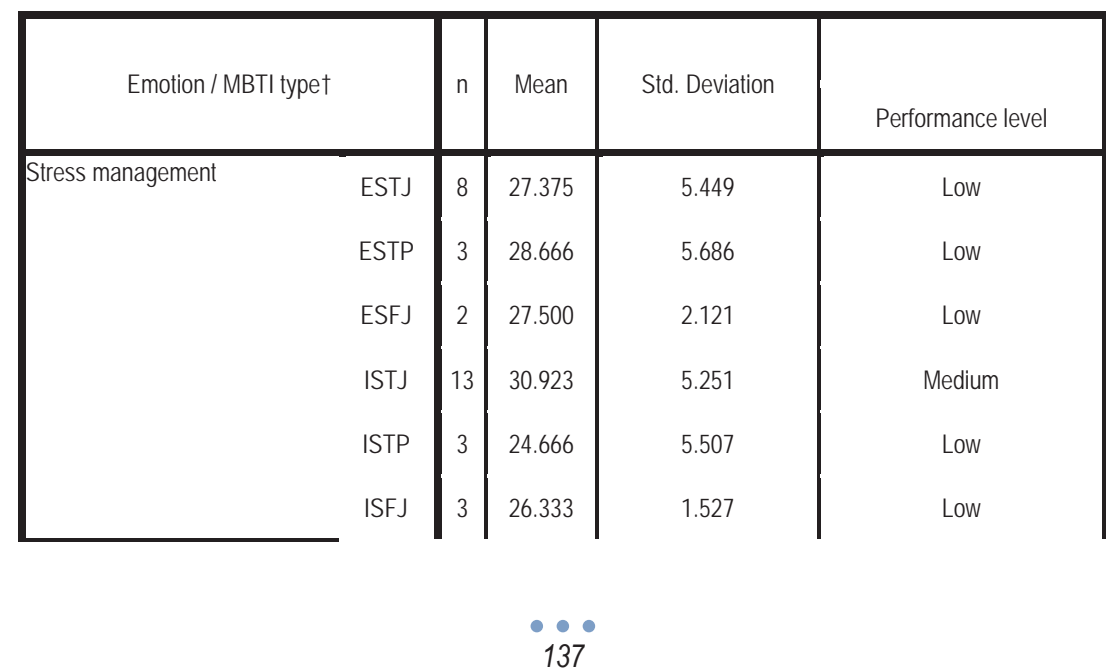




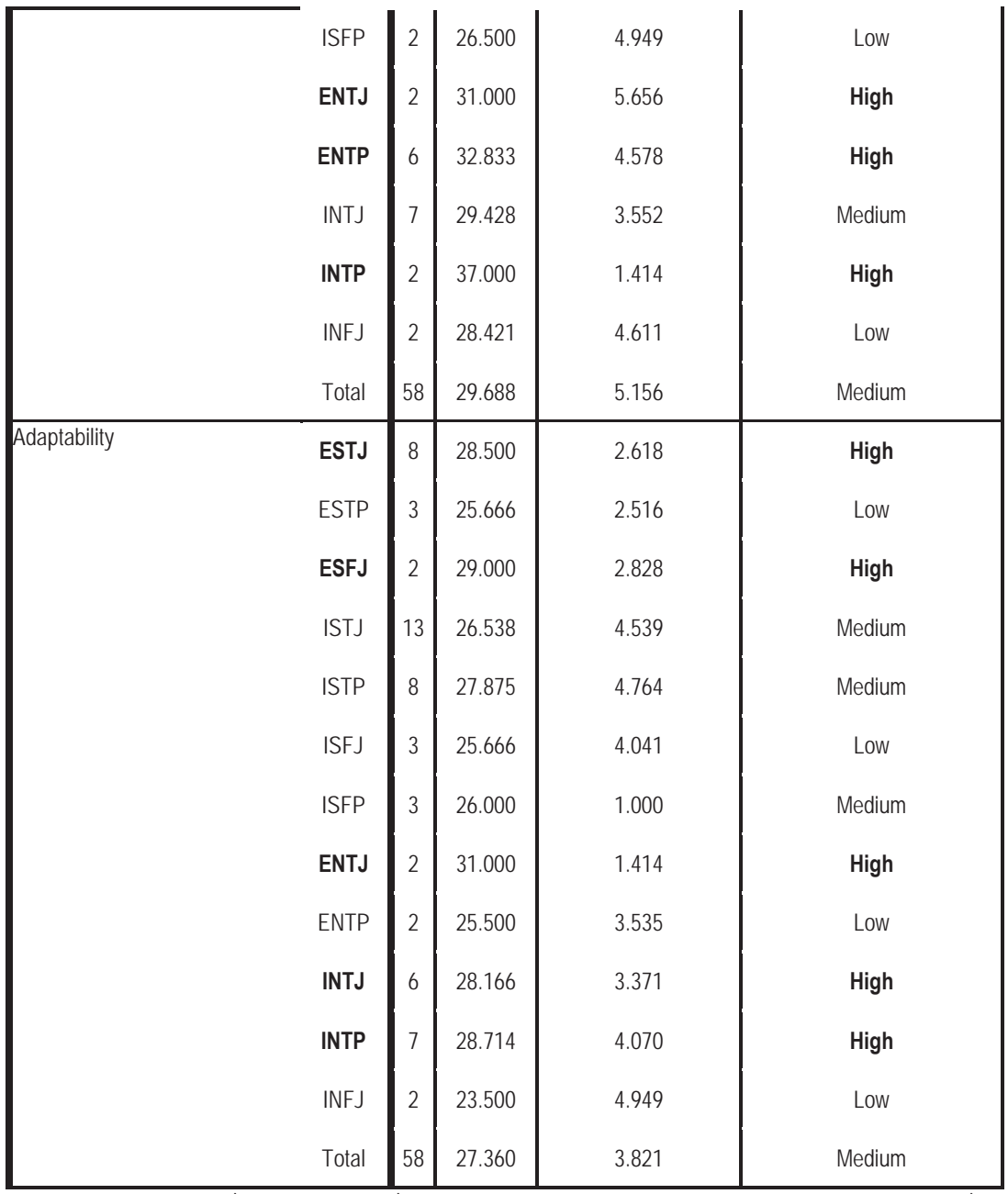

†Two MBTI personality types (ENFJ and ENFP) were not represented in the sample. A further two types (ESFP and INFP) had only one student each and were thus excluded from this analysis

\subsection{Performance of MBTI types on general mood and positive impression El variables}

The most common and widely used emotional intelligence strategy by participants in the present study was general mood. Eight MBTI personality types ( $n=34$ or $59 \%$ ) scored high on the general mood variable (see highlighted abbreviations and words in Table 8). There was also a tendency among four personality types to use positive impression highly. 
Table 8: Mean scores of MBTI types on the BarOn general mood and positive impression variables $(N=58)$

\begin{tabular}{|c|c|c|c|c|c|}
\hline \multicolumn{2}{|c|}{ Emotion / MBTI type $\dagger$} & $n$ & Mean & Std. Deviation & Performance level \\
\hline \multirow[t]{13}{*}{ General mood } & ESTJ & 8 & 43.250 & 6.430 & High \\
\hline & ESTP & 3 & 41.666 & 2.516 & High \\
\hline & ESFJ & 2 & 43.000 & 0.000 & High \\
\hline & ISTJ & 13 & 40.307 & 4.460 & Medium \\
\hline & ISTP & 8 & 40.375 & 4.470 & Medium \\
\hline & ISFJ & 3 & 43.333 & 3.214 & High \\
\hline & ISFP & 3 & 41.000 & 2.645 & High \\
\hline & ENTJ & 2 & 44.500 & 0.707 & High \\
\hline & ENTP & 2 & 40.500 & 2.121 & Medium \\
\hline & INTJ & 6 & 41.166 & 4.400 & High \\
\hline & INTP & 7 & 41.285 & 4.572 & High \\
\hline & INFJ & 2 & 37.000 & 2.828 & Low \\
\hline & Total & 58 & 41.262 & 4.250 & High \\
\hline \multirow[t]{13}{*}{ Positive impression } & ESTJ & 8 & 16.000 & 2.976 & High \\
\hline & ESTP & 3 & 15.00 & 2.645 & Medium \\
\hline & ESFJ & 2 & 18.500 & 0.707 & High \\
\hline & ISTJ & 13 & 14.076 & 3.402 & Medium \\
\hline & ISTP & 8 & 14.750 & 1.832 & Medium \\
\hline & ISFJ & 3 & 16.666 & 1.527 & High \\
\hline & ISFP & 3 & 15.666 & 3.785 & Medium \\
\hline & ENTJ & 2 & 17.000 & 1.414 & High \\
\hline & ENTP & 2 & 15.500 & 3.535 & Medium \\
\hline & INTJ & 6 & 15.333 & 1.966 & Medium \\
\hline & INTP & 7 & 12.571 & 1.988 & Low \\
\hline & INFJ & 2 & 14.500 & 0.707 & Low \\
\hline & Total & 58 & 14.852 & 2.749 & Low \\
\hline
\end{tabular}

†Two MBTI personality types (ENFJ and ENFP) were not represented in the sample. A further two types (ESFP and INFP) had only one student each and were thus excluded from this analysis

Despite categorizing the mean scores of the 12 MBTI personality types as low, medium, and high (in Tables 6-8), these designations were arbitrary as stated earlier and there was no statistically significant difference between the mean scores of the 12 personality types on any of the six El scales. This claim is substantiated by the evidence provided in Table 9.

Table 9: One-Way ANOVA of MBTI types on the BarOn emotional intelligence variables $(N=58)$

\begin{tabular}{|l|c|c|c|}
\hline Variables & Groups $\dagger$ & $\mathrm{F}(11,58)$ & Sig. (2-tailed) \\
\hline Intrapersonal & $12 \mathrm{MBTI}$ Types & 1.066 & 0.410 \\
\hline Interpersonal & $12 \mathrm{MBTI}$ Types & 0.708 & 0.746 \\
\hline Stress management & $12 \mathrm{MBTI}$ Types & 1.323 & 0.234 \\
\hline Adaptability & $12 \mathrm{MBTI}$ Types & 0.879 & 0.579 \\
\hline General mood & $12 \mathrm{MBTI}$ Types & 0.506 & 0.910 \\
\hline Positive impression & $12 \mathrm{MBTI}$ Types & 1.350 & 0.220 \\
\hline
\end{tabular}

†For the 4-letter codes of the personality types under reference see Tables 5-7above

\section{Discussion and Implications}

The MBTI personality preferences and types are described in detail in the technical manual for the instrument (see Myers, 1962; Briggs-Myers \& Briggs, 1985). Due to brevity requirements, the full explanations of the MBTI profiles were 
outside the scope and objectives of the present study.

Regarding the relationship between personality preferences and El variables, note that the majority of the correlation coefficients (both positive and negative) in Table 5 are very low. This finding points to the fact that personality and emotional intelligence are not highly related dispositions.

High scoring MBTI personality types on the intrapersonal El scale, indicated by bold letters in Table 6 are, according to BarOn and Parker (2000), said to be individuals who understand their emotions well and can express or communicate their feelings and needs effectively. However, high scorers on the interpersonal El scale are described as people who are likely to have satisfying interpersonal relationships, are good listeners and able to understand or appreciate the feelings of others (BarOn and Parker, 2000).

In Table 7, individuals who score high on the stress management scale of El are generally calm and can withstand pressure whereas those who score high on the adaptability scale tend to be flexible, realistic and effective in addressing change (BarOn and Parker, 2000).

According to BarOn and Parker (2000), people who score high on the general mood scale (Table 8) of the El test are optimistic individuals who have a positive outlook and are generally pleasant work or be with. However, high scorers on the positive impression domain are persons who are overly inclined to portray a positive image of the self and may be good at exaggerating responses or faking good thereby distorting the validity of the findings. Their scores and profiles must be interpreted carefully or cautiously.

While emphasis in presenting and discussing the findings in Tables 6-8 was placed on the high scorers, the opposite concerning the low scorers is also true. It was observed from these tables that different MBTI personality types focused on using different kinds of emotional intelligence. The most common form of El strategy used by the majority of the personality types ( $8, n=34$ or $59 \%)$ was general mood followed by adaptability $(5, n=25$ or $43 \%)$. At a minimum level, each El variable was used highly by at least three different MBTI personality types. Not all the16 MBTI types were, however, represented in the study sample.

\section{Conclusion and Recommendations}

Based on the findings of the present case study, there is a low-level relationship between personality and emotional intelligence. The study needs to be replicated using large samples from student teacher populations (or other categories of tertiary students and members of the general public) to confirm or refute the current findings. The results of similar large-scale investigations could be used as a basis for providing counseling and psychotherapy interventions to distressed people who need help on how to use personality and emotional intelligence effectively to alleviate their problem(s).

\section{Limitations of the Study}

The present study was informed by two main limitations. First, though random, the sample was relatively small for results to be generalized to similar graduate student teachers elsewhere. Second, as an exploratory case study using self-report survey instruments, the findings could not show cause-and-effect relations among the variables investigated due to problems of internal validity. Despite these limitations, the exploratory case study generated results that merited the investigation to be repeated using a larger sample in Brunei and elsewhere. This, in itself, is a finding with important practical significance.

\section{References}

BarOn, R., \& Parker, J. D. A. (2000). BarOn Emotional Inventory Quotient Inventory - Youth Version: Technical Manual. North Tonawanda, NY: Multi-Health Systems.

Briggs-Myers, I., \& Briggs, K. C. (1985). Myers-Briggs Type Indicator (MBTI). Palo Alto, CA: Consulting Psychologists Press.

Goleman, D. (1995). Emotional intelligence. New York, NY: Bantam Books.

Hamid, M. H. S., Shahrill, M., Matzin, R., Mahalle, S., \& Mundia, L. (2013). Barriers to mathematics achievement in Brunei secondary school students: Insights into the roles of mathematics anxiety, self-esteem, proactive coping, and test stress. International Education Studies, 6 (11), 1-14.

Larsen, R. J., \& Bus, D. M. (2002). Personality psychology: Domains of knowledge about human nature. Boston, MA: McGraw-Hill.

Matzin, R., Shahrill, M., Mahalle, S., Hamid, M. H. S., \& Mundia, L. (2013). A Comparison of Learning Styles and Study Strategies Scores of Brunei Secondary School Students by Test Anxiety, Success Attributions, and Failure Attributions: Implications for Teaching At-risk and Vulnerable Students. Review of European Studies, 5 (5), 119-127. 
Mundia, L. (2010a). Prevalence of depression, anxiety and stress in Brunei student teachers. Internet Journal of Mental Health, 6(2). Available online at: http://www.ispub.com/journal/the_internet_journal_of_mental_health.html

Mundia, L. (2010b). Brunei trainee teachers' coping strategies for stressful situations. International Journal of Psychological Studies, 2 (1), 79-88.

Mundia, L. (2010c). Implementation of SPN21 curriculum in Brunei Darussalam: A review of selected implications on school assessment reforms. International Education Studies, 3 (2), 119-129.

Mundia, L. (2012). Policy changes in Brunei teacher education: Implications for the selection of trainee teachers. The Education Forum, 76 (3), 326-342.

Myers, L. B. (1962). Manual: The Myers-Briggs Type Indicator. Princeton, NJ: Educational Testing Services.

Salovey, P. \& Mayer, J. D. (1990). Emotional intelligence. Imagination, Cognition and Personality, 9, 185-211.

Singh, M. (2015). Emotional intelligence in STEM. Mathematics Today, 51(2), 75-77.

Tait, K., \& Mundia, L. (2012). Preparing teachers to meet the challenges of inclusive education in Negara Brunei Darussalam. In C. I. Forlin (Ed.), Future directions for inclusive teacher education: An international perspective (pp. 60-69). Hong Kong: Routledge/Francis \& Taylor. 